\title{
Non-recombinant display of the $B$ subunit of the heat labile toxin of Escherichia coli on wild type and mutant spores of Bacillus subtilis
}

\author{
Rachele Isticato ${ }^{1}$, Teja Sirec ${ }^{1}$, Lucia Treppiccione ${ }^{2}$, Francesco Maurano ${ }^{2}$, Maurilio De Felice ${ }^{1}$, Mauro Rossi ${ }^{2}$
} and Ezio Ricca ${ }^{1 *}$

\begin{abstract}
Background: Mucosal infections are a major global health problem and it is generally accepted that mucosal vaccination strategies, able to block infection at their entry site, would be preferable with respect to other prevention approaches. However, there are still relatively few mucosal vaccines available, mainly because of the lack of efficient delivery systems and of mucosal adjuvants. Recombinant bacterial spores displaying a heterologous antigen have been shown to induce protective immune responses and, therefore, proposed as a mucosal delivery system. A non-recombinant approach has been recently developed and tested to display antigens and enzymes.

Results: We report that the binding subunit of the heat-labile toxin (LTB) of Escherichia coli efficiently adsorbed on the surface of Bacillus subtilis spores. When nasally administered to groups of mice, spore-adsorbed LTB was able to induce a specific immune response with the production of serum IgG, fecal slgA and of IFN- $\gamma$ in spleen and mesenteric lymph nodes (MLN) of the immunized animals. Dot blotting experiments showed that the non-recombinant approach was more efficient than the recombinant system in displaying LTB and that the efficiency of display could be further increased by using mutant spores with an altered surface. In addition, immunofluorescence microscopy experiments showed that only when displayed on the spore surface by the non-recombinant approach LTB was found in its native, pentameric form.

Conclusion: Our results indicate that non-recombinant spores displaying LTB pentamers can be administered by the nasal route to induce a Th1-biased, specific immune response. Mutant spores with an altered coat are more efficient than wild type spores in adsorbing the antigen, allowing the use of a reduced number of spores in immunization procedures. Efficiency of display, ability to display the native form of the antigen and to induce a specific immune response propose this non-recombinant delivery system as a powerful mucosal vaccine delivery approach.
\end{abstract}

\section{Background}

Several vaccination strategies based on the development of microbial and viral systems to deliver molecules with antigenic properties have been proposed and recently reviewed [1-4]. In this context, bacterial endospores have also been considered to display heterologous antigens on their surface $[5,6]$. Endospores are produced by Grampositive microorganisms mainly belonging to the Bacillus and Clostridium genera and including more than 1,000 species [6]. The endospore (spore), a quiescent cellular type produced in response to harsh environments,

\footnotetext{
*Correspondence: ericca@unina.it

'Department of Biology, Federico II University, Naples, Italy

Full list of author information is available at the end of the article
}

can survive in its dormant state for long periods, resisting to a vast range of stresses such as high temperature, dehydration, absence of nutrients and presence of toxic chemicals. When the environmental conditions ameliorate, the spore germinates originating a vegetative cell able to grow and sporulate [7]. The ability of the spore to survive non-physiological conditions is, in part, due to its surface structures: the coat, formed by at least seventy different proteins (Cot proteins) organized in an inner and an outer part [7] and the crust, a recently discovered outermost layer of the spore [8].

A number of reasons support the use of the spore as a vaccine delivery system. The remarkable and well documented resistance of spores to various environmental

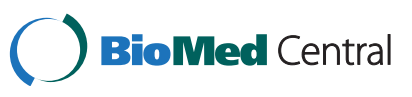


and toxic effects $[6,9]$ ensures high stability of the display system. Proteins to be displayed on the spore are produced in the mother cell compartment of the sporangium and are assembled around the forming spore without the need to be translocated across a membrane, thus eliminating the size constrains of cell-based display systems $[5,6,9]$. The safety record of several endospore-forming species [10], makes spores of those species ideal candidates as vehicles to deliver molecules to mucosal surfaces.

The strategy to obtain the spore surface display of heterologous proteins is based on the construction of gene fusions between the gene coding for a selected spore surface protein (carrier) and the heterologous DNA coding for the protein to be displayed [5]. By this approach a variety of heterologous proteins have been displayed and recombinant spores proposed as vaccine vehicles [11-13], as biocatalysts [9], or as a bioremediation tool [14]. This strategy, based on the genetic engineering of the host, produces recombinant organisms to be used as a live biotechnological tool.

The release of live recombinant organisms into nature raises concerns over the use and clearance of genetically modified microorganisms and is a major drawback of all microbe-based display systems [15]. To overcome this obstacle, a non-recombinant approach to use spores as a display system has been recently proposed and model proteins efficiently exposed. The mammalian NADPHcytochrome P450 reductase [16], the Escherichia coli phytase [17], the beta-galactosidase of Alicyclobaccilus acidocaldaricus [18] and a collections of antigens (TTFC of Clostridium tetani, PA of Bacillus anthracis, Cpa of Clostridium perfringens and glutathione $\mathrm{S}$ transferase of Shistosomas japonica) [19] were all adsorbed to spores and shown to either retain their specific activity [16-18] or induce specific and protective immune responses in mucosally immunised mice [19]. Spore adsorption resulted to be more efficient when the $\mathrm{pH}$ of the binding buffer was acidic $(\mathrm{pH} 4)$ and less efficient or totally inhibited at $\mathrm{pH}$ values of 7 or $10[18,19]$. A combination of electrostatic and hydrophobic interactions between spores and antigens were suggested to drive the adsorption, that was shown to be not dependent on specific spore coat components but rather on the negatively charged and hydrophobic surface of the spore [19]. However, at least in the case of the betagalactosidase of $A$. acidocaldaricus, the electrostatic forces were not found essential in the adsorption to the spore surface [18]. The same study also showed that the interaction with the spore protected the enzyme from exposure to conditions of acidic $\mathrm{pH}$ and high temperatures and that mutants with severely altered spore surface interacted more efficiently than isogenic wild type spores with the beta-galactosidase [18].

In the present work we used a well-characterized antigen, the binding subunit of the heat-labile toxin (LTB) of E. coli $[20]$ to study spore adsorption. Since LTB has been previously displayed on the spore surface by the recombinant approach [11] it was possible to compare the efficiency of display of the two approaches. Here we first show that LTB can be adsorbed to B. subtilis spores and that the adsorbed antigen induces a specific immune response in mucosally immunized mice. Then, we show that LTB is displayed more efficiently by the nonrecombinant than by the recombinant approach and that mutant spores are more efficient than isogenic wild type spores. Finally, we show that only by the nonrecombinant approach LTB is displayed in its active pentameric form.

\section{Results and discussion}

\section{LTB of $E$. coli adsorbs to $B$. subtilis spores}

Aliquots $(2.0 \mu \mathrm{g})$ of LTB, over-expressed in E. coli and purified by affinity chromatography columns (Methods), were incubated in $200 \mu \mathrm{l}$ of PBS buffer with $2.0 \times 10^{9}$ spores of the B. subtilis strain PY79 [21], purified by renographin gradient [22]. After one hour of incubation at $25^{\circ} \mathrm{C}$ spores were collected by centrifugation and surface proteins extracted by SDS-DTT treatment [18]. Proteins were then analyzed by western blot with antiLTB antibody [11] and LTB was found among the proteins extracted from the spore surface (Figure 1A). As previously reported for other antigens [19] and an enzyme [18], the adsorption was more efficient when the binding reaction was performed at $\mathrm{pH} 4.0$ than at $\mathrm{pH}$ 7.0 and was almost abolished at $\mathrm{pH} 10.0$ (Figure 1A).

In order to assess the amount of LTB adsorbed on the spore surface, we fractionated by centrifugation the adsorption reaction mixture obtaining a pellet with the spores and LTB bound to them and a supernatant with unbound, free LTB. Both fractions were analyzed by dot blot with anti-LTB antibody (Figure 1B) and the intensity of the various spots quantified by a densitometric analysis. In our ex-

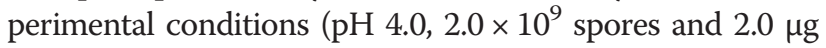
of purified LTB in $200 \mu \mathrm{l}$ ) about 2\% of LTB was left free in the supernatant (Table 1) while about $80 \%$ of it was detected in the pellet fraction (Table 2) and therefore bound to spore. The remaining $18 \%$ of LTB used in the adsorption reaction was either lost in the washing steps of the dot blot experiment or degraded.

\section{Spore-adsorbed LTB induces a specific immune response in nasally immunized mice}

In a previous study, the gene coding for LTB was fused to the gene coding for the spore coat protein CotC and the recombinant strain of $B$. subtilis shown to display an average of $9.6 \times 10^{-5} \mathrm{pg}$ of CotC-LTB per spore [11]. Nine doses of $1.0 \times 10^{10}$ recombinant spores (corresponding to $0.55 \mu \mathrm{g}$ of LTB/dose for a total of $4.95 \mu \mathrm{g}$ of LTB) were used to mucosally immunize groups of mice and the LTB-specific immune response monitored [11]. 


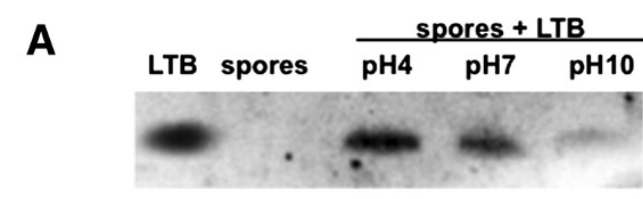

\section{B}
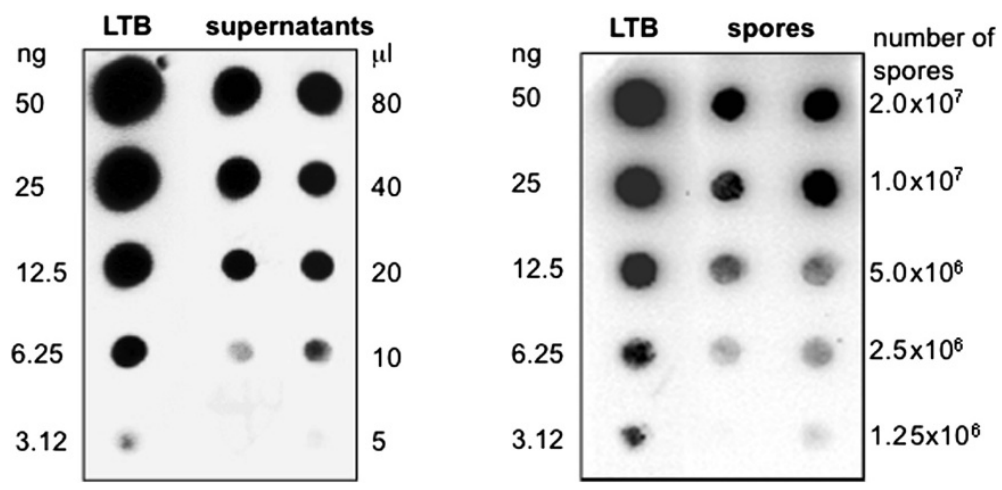

Figure 1 Visualization of spore adsorption by western and dot blotting experiments. (A) Upon adsorption with purified LTB at various pH conditions, spore surface proteins were extracted by SDS-DTT treatment, fractionated on SDS-PAGE and analyzed by western blot. (B) The adsorption mixture $(200 \mu \mathrm{l})$ was fractionated by centrifugation and different amounts of pellet (spores) and supernatant (free LTB) fractions were analyzed by dot blot. Serial dilutions of purified LTB were used as a standard. Immuno-reactions in A and B were performed with anti-LTB antibody [11] and anti-rabbit secondary antibody conjugated with the horseradish peroxidase.

In particular, the production of low levels of LTBspecific serum IgG and fecal sIgA was observed [11]. To analyze whether spore-adsorbed LTB molecules were also able to induce an immune response, groups of mice were nasally immunized with purified LTB $(2.0 \mu \mathrm{g} / \mathrm{dose})$, spores alone $\left(2.0 \times 10^{9} /\right.$ dose $)$ or spore-adsorbed LTB $\left(2.0 \times 10^{9}\right.$ spores adsorbed with $2.0 \mu \mathrm{g}$ of LTB/dose). Animals were dosed once a week for 8 weeks and were sacrificed for analysis one week after the last dose. As calculated in the previous paragraph, $2.0 \times 10^{9}$ spores adsorbed with $2.0 \mu \mathrm{g}$ of LTB displayed about $1.6 \mu \mathrm{g}$ of LTB ( $80 \%$ of the total LTB), therefore, eight doses of spores carried $12.8 \mu \mathrm{g}$ of LTB, about 2.5 -fold more than that delivered by the recombinant approach but using a 5 -fold lower number of spores $\left(2.0 \times 10^{9}\right.$ instead of $1.0 \times 10^{10}$ per dose). A statistically higher production of fecal sIgA, indicative of a

Table 1 Densitometric analysis of dot blot experiments with the supernatants of the adsorption reaction with wild type spores

\begin{tabular}{lcccc}
\hline LTB source & $\begin{array}{c}\text { Amount of } \\
\text { sample used }\end{array}$ & $\begin{array}{c}\text { Density } \\
\left(\mathbf{O D} / \mathbf{m m}^{2}\right)\end{array}$ & $\begin{array}{c}\text { Amount } \\
\text { of LTB }(\mathbf{n g})\end{array}$ & $\begin{array}{c}\text { Amount of LTB } \boldsymbol{\mu g} \\
\text { in } \mathbf{2 0 0} \boldsymbol{\mu l}(\mathbf{\%} \text { total) }\end{array}$ \\
\hline Purified LTB & $12.50 \mathrm{ng}$ & 20.125 & $\mathrm{NA}$ & $\mathrm{NA}$ \\
& $6.25 \mathrm{ng}$ & 8.753 & $\mathrm{NA}$ & $\mathrm{NA}$ \\
& $3.12 \mathrm{ng}$ & 3.696 & $\mathrm{NA}$ & $\mathrm{NA}$ \\
Free LTB & $40 \mu \mathrm{l}$ & 13.211 & 8.8 & $0.04(2.2)$ \\
& $20 \mu \mathrm{l}$ & 6.689 & 3.9 & $0.03(1.9)$ \\
& $10 \mu \mathrm{l}$ & 3.507 & 2.2 & $0.04(2.2)$ \\
\hline
\end{tabular}

mucosal immune response, was observed in mice immunized with spore-adsorbed LTB than in mice immunized with spores alone (negative control), whereas purified LTB was unable to induce SIgA at the tested dose (Figure $2 \mathrm{~A}$ ). The analysis of serum antibodies showed that both anti-LTB IgA (Figure 2B) and IgG (Figure 2C) titers were significantly increased following administration of spore adsorbed LTB in comparison to antigen alone. We speculate that the ability of nasally administered sporeadsorbed LTB to induce a stronger immune response than purified LTB could be related to an increased antigen uptake by immune competent cells or, alternatively, to a reduced antigen degradation, as previously shown for the beta-galactosidase of $A$. acidocaldaricus [18]. Further experiments are required to fully address this issue.

Table 2 Densitometric analysis of dot blot experiments with the pellets of the adsorption reaction with wild type spores

\begin{tabular}{lcccc}
\hline $\begin{array}{l}\text { LTB } \\
\text { source }\end{array}$ & $\begin{array}{c}\text { Amount of } \\
\text { sample used }\end{array}$ & $\begin{array}{c}\text { Density } \\
\left(\mathbf{O D} / \mathbf{m m}^{2}\right)\end{array}$ & $\begin{array}{c}\text { Amount } \\
\text { of LTB }(\mathbf{n g})\end{array}$ & $\begin{array}{c}\text { Amount of LTB }(\boldsymbol{\mu g} / \\
\left.\mathbf{2 . 0} \times 1 \mathbf{0}^{\mathbf{9}} \text { spore }\right) \\
(\% \text { total) }\end{array}$ \\
\hline Purified LTB & $25.00 \mathrm{ng}$ & 12.259 & $\mathrm{NA}$ & $\mathrm{NA}$ \\
& $12.50 \mathrm{ng}$ & 6.689 & $\mathrm{NA}$ & $\mathrm{NA}$ \\
& $6.25 \mathrm{ng}$ & 3.507 & $\mathrm{NA}$ & $\mathrm{NA}$ \\
Bound LTB & $1.0 \times 10^{7}$ & 5.219 & 9.6 & $1.92(96)$ \\
& $5.0 \times 10^{6}$ & 2.756 & 4.3 & $1.72(86)$ \\
& $2.5 \times 10^{6}$ & 1.450 & 1.5 & $1.20(60)$ \\
\hline
\end{tabular}



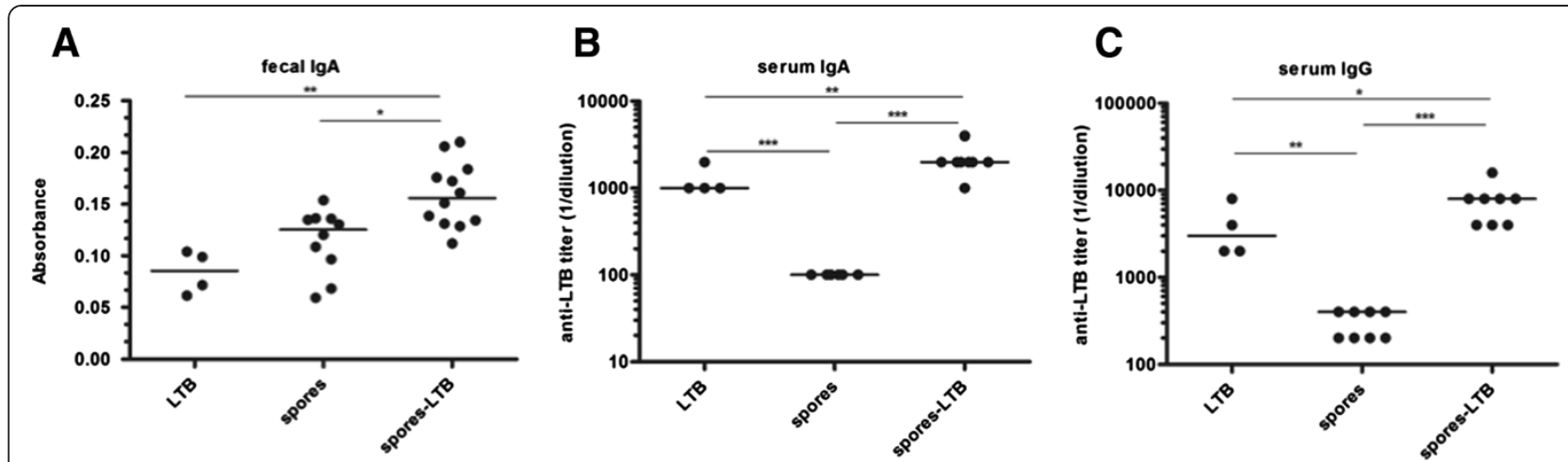

Figure 2 Antibody production in mice immunized with spore-adsorbed LTB. BALB/C mice were treated with antigen alone $(n=4)(L T B)$, spores alone $(n=10)$ (spores) or LTB-adsorbed spores ( $n=12)$ (spores-LTB). (A) Anti-LTB IgA detected in fecal pellet at the end of treatment; absorbance values are shown. Anti-LTB $\lg A$ (B) and $\lg G(\mathbf{C})$ levels detected in mice serum; reciprocal endpoint titers are shown. Bars represent median values. Results are representative of two independent experiments. ${ }^{*}, P<0.05 ;{ }^{* *}, P<0.01,{ }^{* * *}, P<0.001$.

The phenotype of the induced immune response was then examined. The analysis of IgG subclasses did not show a preferential increase of IgG1 or IgG2a subtypes (Figure $3 \mathrm{AB}$ ). Spleen and mesenteric lymph nodes (MLN) of immunized animals were analyzed for LTB-specific production of IL-4 and interferon- $\gamma$ (IFN- $\gamma$ ). While IL-4 was not produced at detectable levels (not shown), IFN- $\gamma$ was produced by both spleen and MLN cells of mice immunized with spore-adsorbed LTB at levels statistically higher than by those immunized with purified LTB (Figure 3CD). Although a comparison between our data and those previously obtained with recombinant spores displaying LTB [11] is not possible for the different immunization route (oral vs. nasal) and the different amounts of antigen
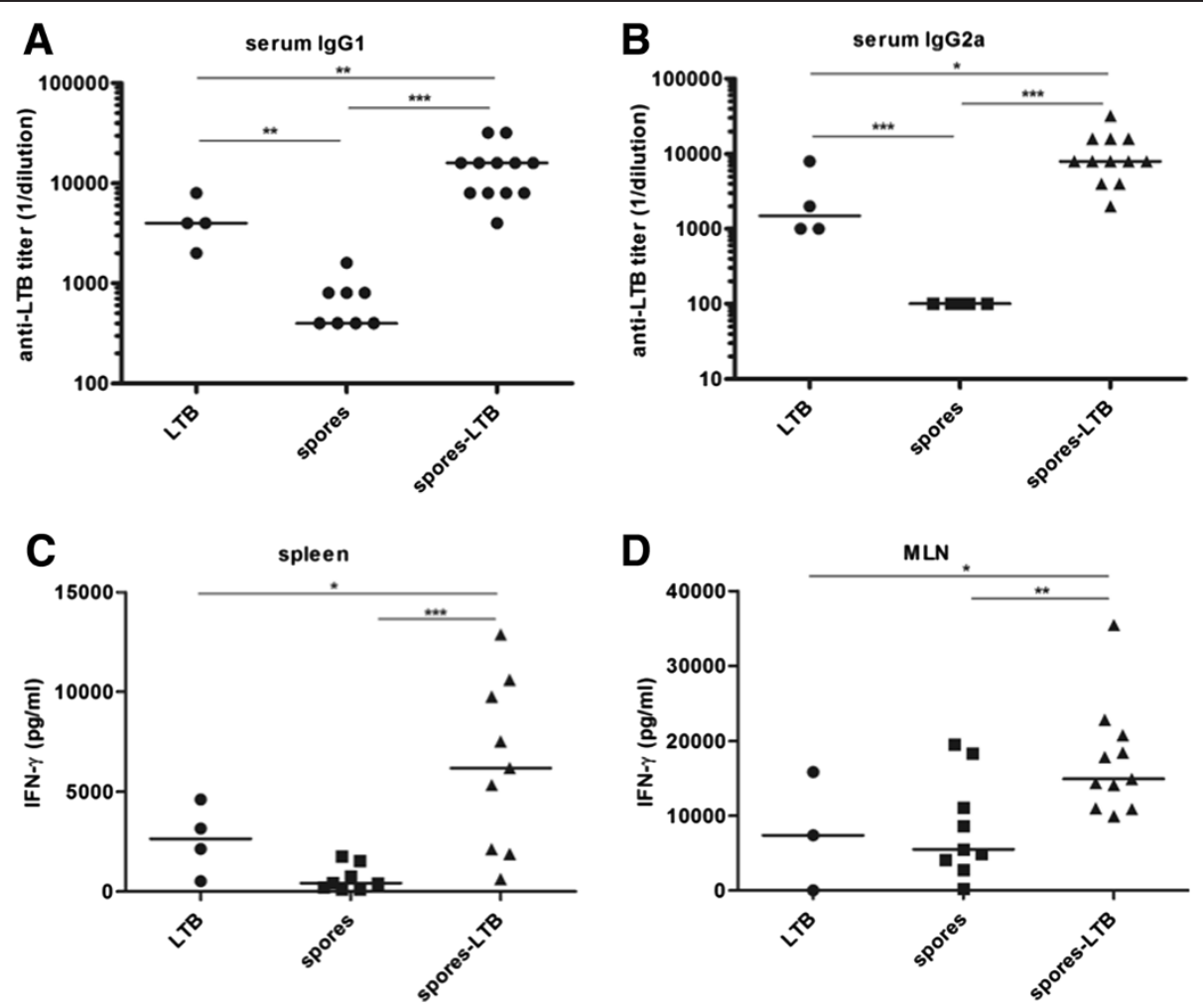

Figure 3 Characterization of the immune response. A Th1-like immunity was induced in BALB/C mice following administration of LTBadsorbed spores. Anti-LTB IgG1 (A) and IgG2a (B) levels detected in mice; reciprocal endpoint titers are shown. Antigen-specific IFN- $\gamma$ levels secreted in vitro from spleen (C) and MLN cells (D); data are reported after subtracting the cytokine values detected in the absence of antigen stimulation. Bars represent median values. Results are representative of two independent experiments. ${ }^{*}, P<0.05 ;{ }^{* *}, P<0.01 ;{ }^{* *}, P<0.001$. 
administered (4.95 vs. $12.8 \mu \mathrm{g}$ ), our results confirm the previously reported humoral response. Moreover, the statistically significant production of IFN- $\gamma$ and the lack of detectable levels of LTB-specific IL-4 of immunized animals suggest that the nasal administration of spore-adsorbed LTB promotes a significant cellular (Th1-biased) immune response in both systemic and mucosal compartments. Induction of a Th-1 type of immune response by antigens carried by spores is in agreement with previous observations deriving from experiments with spores displaying different antigens $[19,23]$.

\section{Increased efficiency of LTB display}

The non-recombinant display system was more efficient than the recombinant approach and allowed the delivery of a high amount of antigen with a low number of spores. To verify whether it was possible to further increase the amount of LTB adsorbed to spores we tested a collection of mutants of $B$. subtilis with an altered spore surface. In agreement with previous data obtained with various antigens [19] and an enzyme [18], LTB adsorption was similar in wild type spores (PY79) and in isogenic null mutants lacking $\cot A, \cot B, \cot C, \cot D$ or $\cot G$ (not shown). However, it has also been reported that the spore adsorption of the beta-galactosidase of $A$. acidocaldaricus was significantly increased in $\cot H$ null mutant spores that have a strongly altered coat [18]. We then analyzed the adsorption of LTB to $\cot H$ mutant spores. After one hour of incubation at $25^{\circ} \mathrm{C}$ we fractionated by centrifugation the adsorption reaction as described above, and performed dot blot experiments with anti-LTB antibody on both supernatant (free LTB) and pellet (spore-bound LTB) fractions (Figure 4). A densitometric analysis of the various spots indicated that the amount of LTB not bound to spores was much lower in the mutant than in the isogenic wild type strain (Figure 4A and Table 3), while spore-bound LTB was much higher in the mutant than in the wild type (Figure 4B and Table 4). Therefore, results of Figure 4 and Tables 3 and 4 indicate that mutant spores with a strongly altered surface are more efficient than wild type spores in adsorbing LTB and confirm previous data on the adsorption of the beta-galactosidase of $A$. acidocaldaricus [18].

Both wild type and $\cot H$ mutant spores were then tested for adsorption with increasing amounts of LTB. Dot blot (Figure 5A) and densitometric analysis (Table 5) of the obtained spots indicated that the amount of spore-bound LTB increased when high amounts of purified LTB were used in the adsorption reaction. With wild type spores about 1.5, 3.4 and 5.5 $\mu$ g of LTB was displayed after adsorption with 2.0, 10.0 or $20.0 \mu \mathrm{g}$ of purified LTB, respectively (Table 5 ). With $\cot H$ mutant spores, the efficiency of adsorption is higher than with wild type spores at all tested LTB concentrations and 1.8, 7.3 and $14.3 \mu \mathrm{g}$ of LTB were displayed on mutant spores using for the
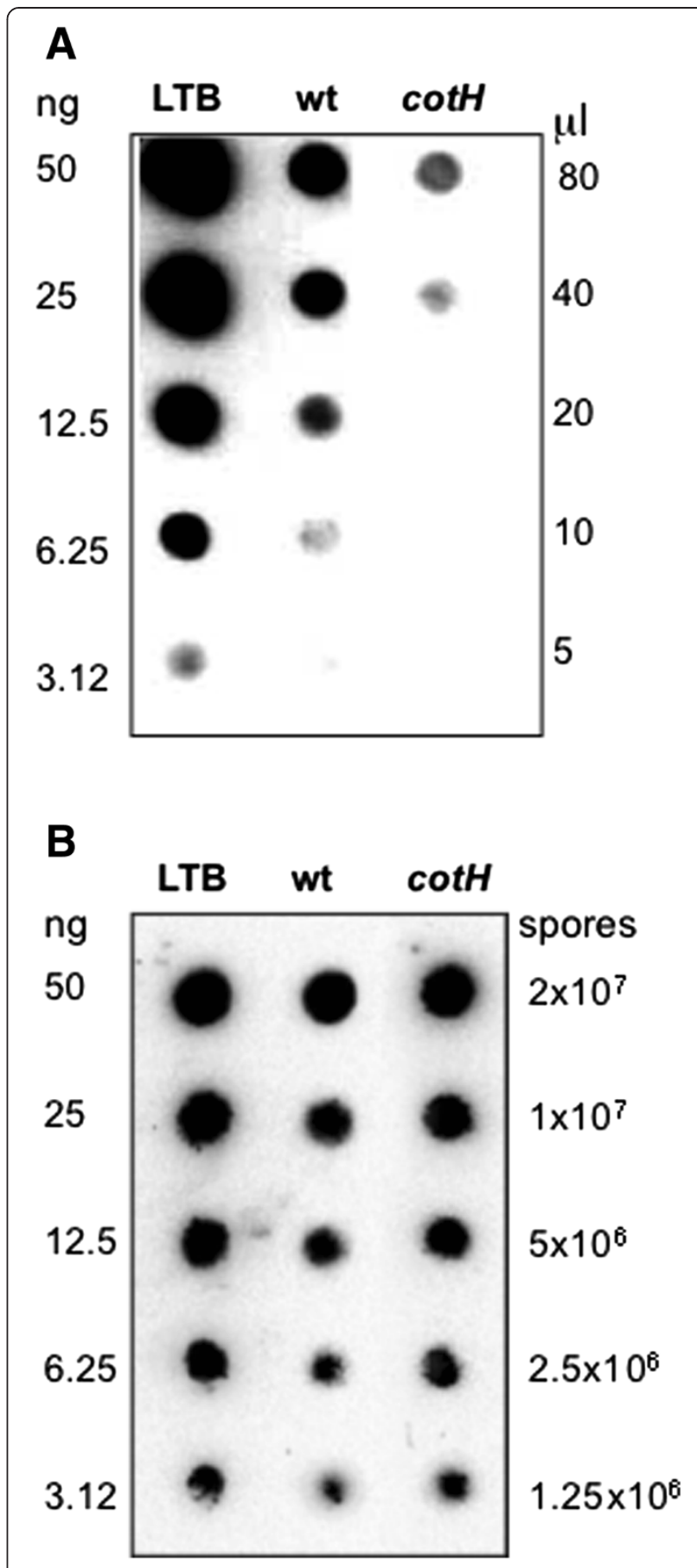

Figure 4 Efficiency of LTB adsorption on wild type and mutant spores. Upon adsorption with $2.0 \mathrm{\mu g}$ of purified LTB the reaction mixture was fractionated by centrifugation. Supernatant (A) and pellet (B) fractions were serially diluted and analyzed by dot blot. Serial dilutions of purified LTB were used as a standard. Immunoreactions in $\mathbf{A}$ and $\mathbf{B}$ were performed with anti-LTB antibody [11] and anti-rabbit secondary antibody conjugated with the horseradish peroxidase 
Table 3 Densitometric analysis of dot blot experiments with the supernatants of the adsorption reaction with wild type and cotH mutant spores

\begin{tabular}{lcccc}
\hline LTB source & $\begin{array}{c}\text { Amount of } \\
\text { sample used }\end{array}$ & $\begin{array}{c}\text { Density } \\
\left(\mathbf{O D} / \mathbf{m m}^{2}\right)\end{array}$ & $\begin{array}{c}\text { Amount } \\
\text { of LTB }(\mathbf{n g})\end{array}$ & $\begin{array}{c}\text { Amount of LTB } \boldsymbol{\mu g} \\
\text { in } \mathbf{2 0 0} \boldsymbol{\mu l} \text { (\% total) }\end{array}$ \\
\hline Purified LTB & $12.50 \mathrm{ng}$ & 25.125 & $\mathrm{NA}$ & $\mathrm{NA}$ \\
& $6.25 \mathrm{ng}$ & 10.875 & $\mathrm{NA}$ & $\mathrm{NA}$ \\
& $3.12 \mathrm{ng}$ & 4.621 & $\mathrm{NA}$ & $\mathrm{NA}$ \\
$\mathbf{w t}$ & $40 \mu \mathrm{l}$ & 16.517 & 9.2 & $0.04(2.0)$ \\
& $20 \mu \mathrm{l}$ & 8.361 & 4.1 & $0.04(2.1)$ \\
& $10 \mu \mathrm{l}$ & 4.383 & 1.9 & $0.03(1.9)$ \\
cotH & $80 \mu \mathrm{l}$ & 7.522 & 3.8 & $0.009(0.4)$ \\
& $40 \mu \mathrm{l}$ & 2.987 & 1.2 & $0.006(0.3)$ \\
\hline
\end{tabular}

adsorption reaction 2.0, 10.0 and $20.0 \mu \mathrm{g}$ of purified LTB, respectively (Table 5). Densitometric data of Table 5 are summarized in Figure 5B and show that with wild type spores (grey bars) the efficiency of LTB display decreased from about $70 \%$ to $30 \%$ when high amounts of purified LTB were used in the adsorption reaction. With $\cot H \mathrm{mu}$ tant spores (black bars in Figure 5) the efficiency of LTB only slightly decreased and remained around $70 \%$ when 10.0 and $20.0 \mu \mathrm{g}$ of purified LTB were used in the adsorption reaction.

\section{Spore-adsorbed LTB is in its active pentameric form}

The heat-labile toxin of $E$. coli is similar to the cholera toxin and is formed by an enzymatically active A subunit and a pentameric non-toxic B subunit (LTB). Only in its pentameric form LTB can bind its receptor, the ganglioside GM1, allowing entry of the A subunit into the host eukaryotic cell. LTB alone is not toxic but able to induce a potent mucosal immunogenic activity. In addition, LTB can exert a mucosal adjuvant activity for coadministered

\begin{tabular}{|c|c|c|c|c|}
\hline $\begin{array}{l}\text { LTB } \\
\text { source }\end{array}$ & $\begin{array}{l}\text { Amount of } \\
\text { sample used }\end{array}$ & $\begin{array}{l}\text { Density } \\
\left(\mathrm{OD} / \mathrm{mm}^{2}\right)\end{array}$ & $\begin{array}{c}\text { Amount } \\
\text { of LTB (ng) }\end{array}$ & $\begin{array}{c}\text { Amount of LTB }(\mu \mathrm{g} / \\
\left.2.0 \times 10^{9} \mathrm{spore}\right) \\
(\% \text { total })\end{array}$ \\
\hline \multirow{3}{*}{$\begin{array}{l}\text { Purified } \\
\text { LTB }\end{array}$} & $25.0 \mathrm{ng}$ & 75.553 & NA & NA \\
\hline & $12.5 \mathrm{ng}$ & 40.385 & NA & NA \\
\hline & $6.25 \mathrm{ng}$ & 22.113 & NA & NA \\
\hline \multirow[t]{3}{*}{ wt } & $1 \times 10^{7}$ & 38.631 & 8.2 & $1.64(82)$ \\
\hline & $5 \times 10^{6}$ & 15.227 & 3.5 & $1.41(70)$ \\
\hline & $2.5 \times 10^{6}$ & 9.238 & 1.6 & $1.29(65)$ \\
\hline \multirow[t]{3}{*}{$\cot H$} & $5 \times 10^{6}$ & 18.527 & 4.7 & $1.90(95)$ \\
\hline & $2.5 \times 10^{6}$ & 7.857 & 2.2 & $1.836(91)$ \\
\hline & $1.25 \times 10^{6}$ & 3.864 & 1.1 & $1.888(94)$ \\
\hline
\end{tabular}

unrelated antigens [24]. Although the mechanism of the adjuvant effects of LTB is not known, such activity strictly depends on LTB ability to bind to its cell receptor GM1, and therefore on the pentameric association of five $B$ subunits [24]. When LTB is expressed in a heterologous bacterium fused to an anchor protein, pentamer formation is impaired [25]. In order to assess whether LTB pentamers were formed when LTB was displayed by the non-recombinant system on the spore surface, an immunofluorescence microscopy analysis with anti-GM1 antibody was performed. Wild type and $\operatorname{cotH}$ mutant spores of $B$. subtilis were adsorbed with $10 \mu \mathrm{g}$ of purified LTB as described above, reacted with GM1 (Merck) and used for immunofluorescence analysis with anti-GM1 antibody. As shown in Figure 6, spores of both strains were fluorescent indicating that GM1 was able to bind the spore surface and, therefore, that LTB pentamers were present on the spore surface. As expected for the high efficiency of LTB adsorption, $\cot H$ mutant spores were more fluorescent than the wild type spores (Figure 6). When wild type or mutant spores were adsorbed with LTB but not treated with GM1, no fluorescence was observed after reaction with antiGM1 antibody (negative control in Figure 6), indicating the specificity of the fluorescent signals observed when GM1 was used. The recombinant strain carrying a $\cot C:: e l t B$ gene fusion and displaying the CotC-LTB fusion on the spore surface [11] was also used for immunofluorescence analysis with anti-GM1 antibody. As shown in Figure 6 no fluorescence was observed around the recombinant spores, indicating that no pentamers were present.

\section{Conclusions}

In this study we analyzed the adsorption of the B subunit of the heat-labile toxin (LTB) of Escherichia coli to spores of Bacillus subtilis. Although the recombinant and non-recombinant display of antigens and enzymes on B. subtilis spores has been reported previously $[5,6,9,11-19]$, our work highlights several new information that significantly improve the potential applications of the spore-based display system. First of all, the non-recombinant spore display approach based on surface absorption turned out to be significantly more efficient than the recombinant approach, the latter being based on the construction of gene fusions between DNA coding for a spore coat protein (carrier) and for LTB (passenger). An average of $9.6 \times 10^{-5} \mathrm{pg}$ of CotCLTB per spore was previously shown to be displayed by a strain carrying a $\cot C:: e l t B$ gene fusion [11]. We report here that using $20.0 \mu \mathrm{g}$ of purified LTB in the adsorption reaction, up to $2.5 \times 10^{-3} \mathrm{pg}$ of LTB per spore are displayed on wild type spores. This about 25 -fold increase of displayed LTB becomes even larger by using mutant spores altered in the spore surface. Indeed, with $\cot H$ null mutant spores, up to $7.0 \times 10^{-3} \mathrm{pg}$ of LTB per spore were displayed, resulting in a 2.5 - and 70 -fold increase with respect to wild type 

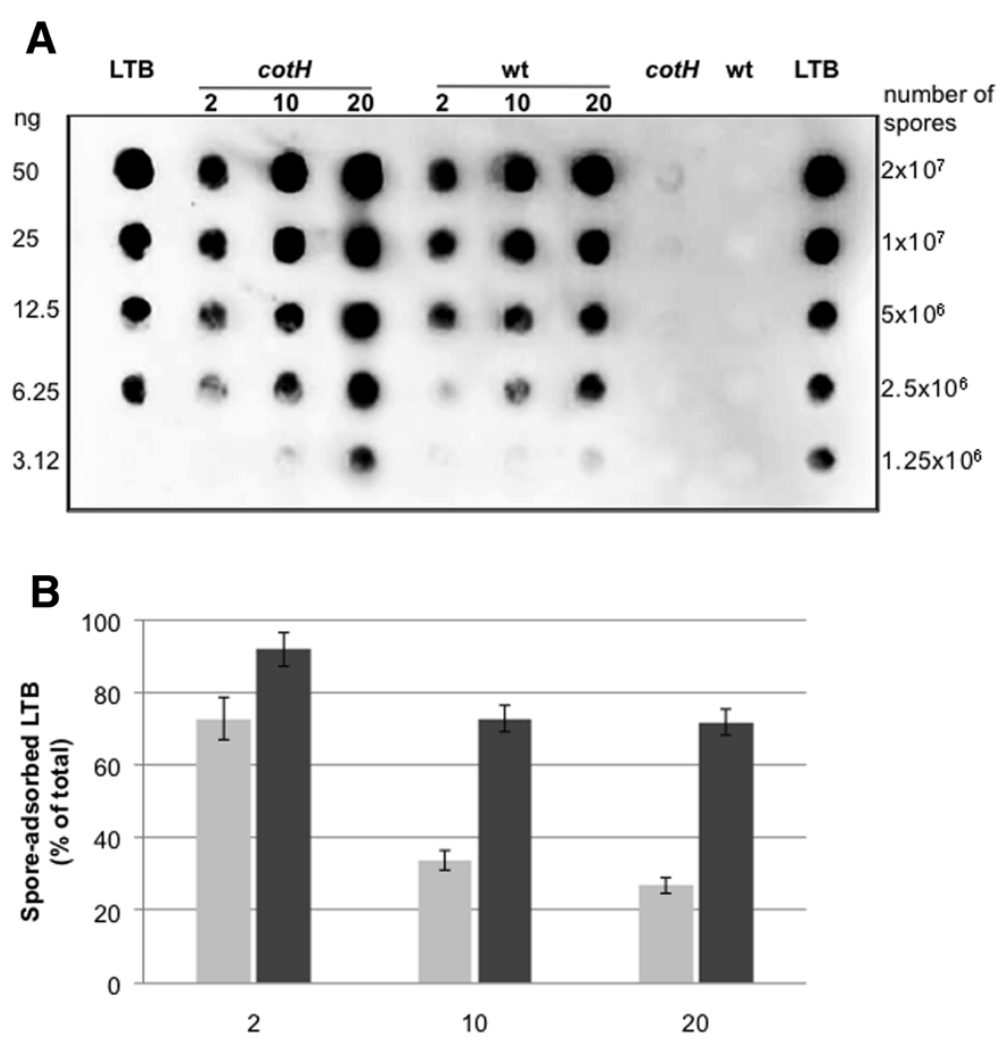

Amount of LTB used in the adsorption reaction $(\mu \mathrm{g})$

Figure 5 Saturation of LTB adsorption. (A) The adsorption reactions were performed with $2.0 \times 10^{9}$ spores of the wild type and cotH mutant strain and with 2.0, 10.0 and $20.0 \mu \mathrm{g}$ of purified LTB. Serial dilutions of purified LTB were used as a standard. Wild type and mutant spores not adsorbed with LTB were used as negative controls. Immuno-reactions were performed with anti-LTB antibody [10] and anti-rabbit secondary antibody conjugated with the horseradish peroxidase. (B) Percentage of LTB bound to the spore surface of wild type (gray bars) or cotH mutant (black bars) spores. The amount of LTB used in the adsorption reaction was considered as 100\%. Error bars represent the standard deviation of each experiments.

spores and to the recombinant approach, respectively. Mutant spores lacking $\mathrm{CotH}$ have been previously characterized $[26,27]$. In addition to $\mathrm{CotH}$ they lack at least nine other coat proteins (CotH-dependent coat proteins) [28], and as a consequence have strong defects in both inner and outer coat [27]. These alterations reduce the total negative charge of the spore [18] and we speculate that they could also affect other physicochemical properties of the spore relevant for adsorption. An increased efficiency of display is particularly relevant when the system is aimed at delivering an antigen to a mucosal surface, since it allows to reduce the number of spores needed to induce an immune response. Nine doses of $1.0 \times 10^{10}$ recombinant spores induce a specific immune response in mice [11]. However, scalingup that number to immunize humans would be extremely difficult or even not realistic, making essential to develop more efficient display systems.

A second main result of this work is that LTB forms pentamers on the spore surface. Consistently with a previous report where LTB was displayed on the surface of Streptococcus gordonii cells [25] also when expressed on the spore surface as a fusion protein with CotC, LTB does not form pentamers (Figure 6). We show here that the native, pentameric form of LTB was observed only when purified LTB was adsorbed to spores. This aspect is crucial since the immunostimulatory activity of LTB largely depends on its ability to bind to its cell receptor, most commonly the ganglioside GM1, which in turn requires the association of $B$ subunits to form a donutshaped pentamer via noncovalent associations. Pentamer formation and interaction with the receptor result in enhanced targeting and access to MHC compartments [29] with the consequent increased activation of antigen presenting cells and $\mathrm{T}$ cells [30].

In conclusion, our work shows that by a nonrecombinant approach LTB can be efficiently displayed in its native pentameric form on the spore surface and that spore-displayed LTB molecules induce a Th1-biased immune response in mice immunized by the nasal route. These data, together with the well established robustness and stability of the spore and the safety record of spores of several species, propose the spore as a very promising platform to display molecules to be presented to the human mucosal surfaces. 
Table 5 Densitometric analysis of dot blot experiments with the pellets of the adsorption reaction with wild type and cotH mutant spores and increasing amounts of LTB

\begin{tabular}{|c|c|c|c|c|}
\hline $\begin{array}{l}\text { LTB } \\
\text { source }\end{array}$ & $\begin{array}{l}\text { Amount of } \\
\text { sample used }\end{array}$ & $\begin{array}{l}\text { Density } \\
\left(\mathrm{OD} / \mathrm{mm}^{2}\right)\end{array}$ & $\begin{array}{c}\text { Amount } \\
\text { of LTB (ng) }\end{array}$ & $\begin{array}{c}\text { Amount of LTB } \\
\mu \mathrm{g} / 2 \times 10^{9} \text { spore } \mu \mathrm{l} \\
\text { (total) }\end{array}$ \\
\hline \multirow{3}{*}{$\begin{array}{l}\text { Purified } \\
\text { LTB }\end{array}$} & $25.0 \mathrm{ng}$ & 122.592 & NA & NA \\
\hline & $12.5 \mathrm{ng}$ & 66.385 & NA & NA \\
\hline & $6.25 \mathrm{ng}$ & 35.721 & NA & NA \\
\hline \multicolumn{5}{|l|}{$2 \mu g$} \\
\hline \multirow[t]{3}{*}{ wt } & $1 \times 10^{7}$ & 36.331 & 7.2 & $1.50(75)$ \\
\hline & $5 \times 10^{6}$ & 22.387 & 3.8 & $1.52(75)$ \\
\hline & $2.5 \times 10^{6}$ & 14.418 & 1.2 & $1.45(72)$ \\
\hline \multirow[t]{3}{*}{$\cot H$} & $5 \times 10^{6}$ & 30.527 & 4.2 & $1.92(96)$ \\
\hline & $2.5 \times 10^{6}$ & 19.157 & 2.3 & $1.86(93)$ \\
\hline & $1.25 \times 10^{6}$ & 9.564 & 1.3 & 1.79 (89) \\
\hline \multicolumn{5}{|l|}{$10 \mu \mathrm{g}$} \\
\hline \multirow[t]{3}{*}{ wt } & $1 \times 10^{7}$ & 98.331 & 19.7 & 3.94 (39) \\
\hline & $5 \times 10^{6}$ & 51.387 & 8.7 & $3.48(35)$ \\
\hline & $2.5 \times 10^{6}$ & 28.418 & 3.6 & $2.88(28)$ \\
\hline \multirow[t]{3}{*}{$\cot H$} & $1 \times 10^{7}$ & 142.37 & 32 & $6.4(64)$ \\
\hline & $5 \times 10^{6}$ & 97.285 & 19 & $7.6(76)$ \\
\hline & $2.5 \times 10^{6}$ & 53.644 & 10 & $8.0(80)$ \\
\hline \multicolumn{5}{|l|}{$20 \mu \mathrm{g}$} \\
\hline \multirow[t]{2}{*}{ wt } & $5 \times 10^{6}$ & 66.778 & 12.8 & $5.1(25)$ \\
\hline & $25 \times 10^{6}$ & 42.422 & 7.5 & $6.0(30)$ \\
\hline \multirow[t]{3}{*}{$\cot H$} & $5 \times 10^{6}$ & 159.87 & 35.2 & $14.3(71)$ \\
\hline & $2.5 \times 10^{6}$ & 87.56 & 17.34 & $13.8(70)$ \\
\hline & $1.25 \times 10^{6}$ & 42.422 & 9.83 & $15.0(75)$ \\
\hline
\end{tabular}

\section{Methods}

\section{Bacterial strains and transformation}

The B. subtilis PY79 strain [21] was used as a wild type. Strain ER220 (cotH null mutant) [26] and all other mutant strains of B. subtilis used in this study were isogenic derivatives of PY79 and have all been described elsewhere [18]. Isolation of plasmid DNA, restriction digestion, ligation of DNA and transformation of E. coli competent cells were carried out by standard methods [31].

\section{Purification of spores and LTB}

Sporulation of wild type and recombinant strains was induced by the exhaustion method. After $30 \mathrm{~h}$ of growth in Difco Sporulation medium (DSM) at $37^{\circ} \mathrm{C}$ with vigorous shaking, spores were collected, washed three times with distilled water and purified by renografin gradient as described before [22]. Spore counts were determined by serial dilution and plate-counting.

A recombinant plasmid containing the eltB gene, excluding the leader peptide coding sequence, of enterotoxigenic strains of E. coli has been previously described [25]. A DNA fragment of 321-bp was cleaved with KpnI and Hin$d$ III restriction enzymes and ligated into the expression vector pRSETA (Invitrogen), previously digested with the same enzymes. The recombinant plasmid carrying an inframe fusion of the 5 ' end of the eltB coding region to six histidine codons under the transcriptional control of a T7 promoter was used to transform competent cells of the $E$. coli strain BL21(DE3) (Invitrogen), yielding strain RH153. This strain was grown in ampicillin-supplemented $(50 \mu \mathrm{g} /$ $\mathrm{ml}$ ) LB medium to an optical density of 0.7 at $600 \mathrm{~nm}$. The T7 promoter was then induced by adding isopropyl- $\beta$ Dthiogalactoside (IPTG; final concentration, $0.5 \mathrm{mM}$ ) to the culture, which was incubated for $4 \mathrm{~h}$ at $37^{\circ} \mathrm{C}$ [32]. The six-His-tagged LTB protein was purified under native conditions using the His-Trap column as recommended by the manufacturer (GE Healthcare Life Science). Purified protein was desalted using the PD10 column (GE Healthcare Life Science) to remove high $\mathrm{NaCl}$ and imidazole concentrations.

\section{Adsorption reaction}

Purified LTB was added to a suspension of $2 \times 10^{9}$ spores in $0,15 \mathrm{M}$ PBS $\mathrm{pH} 4.0$ at $25^{\circ} \mathrm{C}$ in a final volume of $200 \mu \mathrm{l}$. After 1 hour of incubation, the binding mixture was centrifuged (10 $\mathrm{min}$ at $13,000 \mathrm{~g}$ ) to fractionate pellet and supernatant. The pellet was resuspended in $0,15 \mathrm{M} \mathrm{PBS}$ at pH 4.0 to a final concentration of $2 \times 10^{5}$ spores $/ \mu \mathrm{l}$ and store at $4^{\circ} \mathrm{C}$ for further experiments.

\section{Western and dot-blot analysis}

$2.0 \times 10^{8}$ spores adsorbed LTB were resuspended in $20 \mu \mathrm{l}$ of spore coat extraction buffer [22], incubated at $68^{\circ} \mathrm{C}$ for 1 hour to solubilize spore coat proteins and loaded onto a $12 \%$ SDS-PAGE gel. The proteins were then electrotransferred to nitrocellulose filters (Amersham Pharmacia Biotech) and used for Western blot analysis as previously reported [33].

A quantitative determination of the amount of LTB was obtained by dot blot experiments with specific antiLTB antibodies analyzing serial dilutions of purified LTB, binding assay supernatant and spore adsorbed LTB. Filters were then visualized by the ECL-prime (Amersham Pharmacia Biotech) method and subjected to densitometric analysis by Fluor-S Multimager (Bio-Rad).

\section{GM1 binding assay}

$2.0 \times 10^{9}$ spores were adsorbed with $10 \mu \mathrm{g}$ LTB and an aliquot of $2.0 \times 10^{6}$ reacted with $2 \mu \mathrm{g}$ of Monosialotetra hexosyl-ganglioside (GM1)(Merck) in $50 \mu \mathrm{l}$ of $1 \times \mathrm{PBS}$, $\mathrm{pH} 4.0$ for 4 hours at $25^{\circ} \mathrm{C}$. After three washes with PBS, the samples were pretreated with $1 \%$ bovine serum albumin (BSA) - 1× PBS, pH 4.0 for 30 minutes prior to incubation overnight a $4{ }^{\circ} \mathrm{C}$ with the polyclonal anti-GM1 

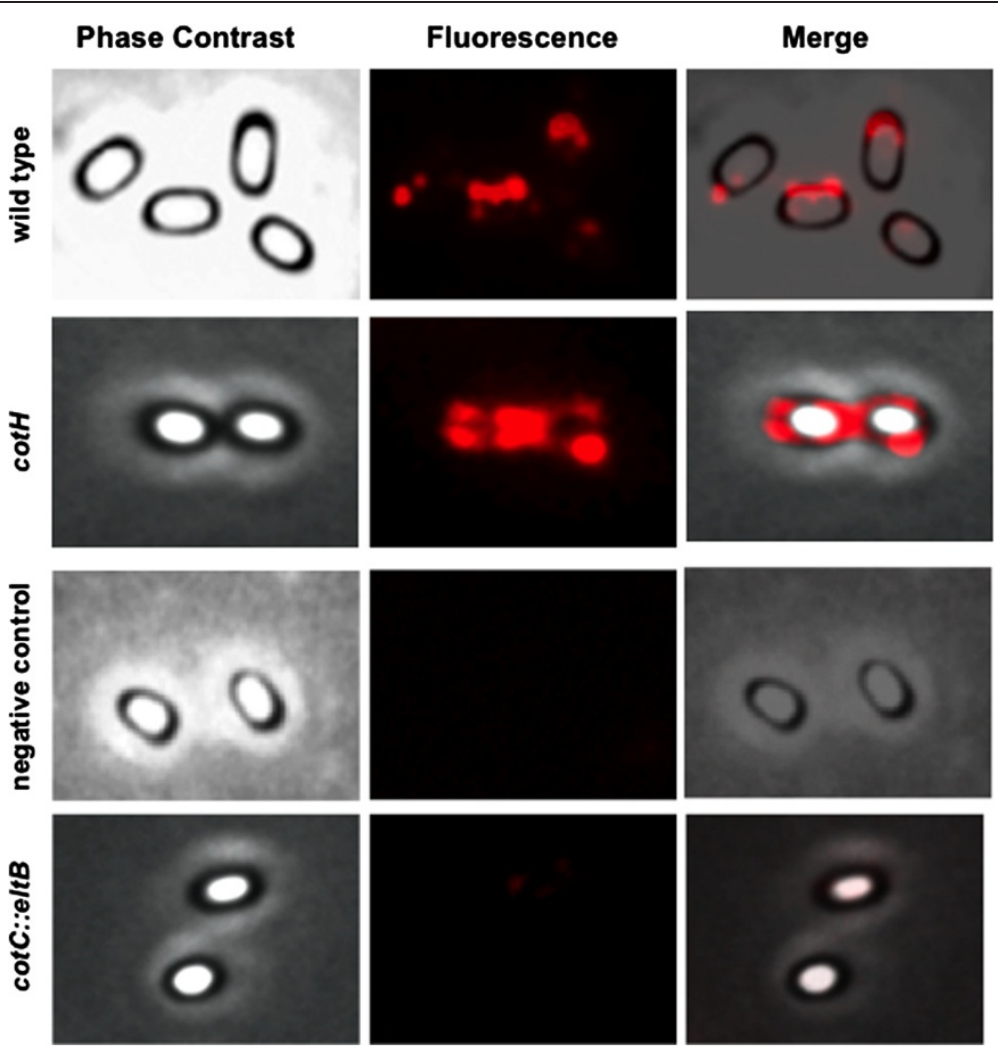

Figure 6 Immunofluorescence microscopy with anti-GM1 antibody. Wild type, cotH mutant and recombinant cotC::eltB spores were adsorbed with $10.0 \mu \mathrm{g}$ of LTB, treated with GM1 and reacted with anti-GM1 antibody and Texas Red conjugated secondary antibody. Spores adsorbed with LTB but not treated with GM1 were also reacted with GM1 antibody (negative control). A representative microscopy field for each strain is observed by phase contrast and immunofluorescence. Merged panels of phase contrast and immunofluorescence are shown. Exposure times were typically in the range of 50-200 ms.

antibodies (rabbit) (Abcam Ltd) diluted 1:10 in PBS-1\% BSA. As a control of the specificity of this technique, both spores alone and spores adsorbed with LTB were not reacted with GM1 and directly treated with antiGM1 antibodies. After three washes, the samples were incubated with a 64-fold diluted anti-rabbit secondary antibody conjugates with Tetramethyl Rhodamine, TRITC (Santa Cruz Biotechnology, Inc.) and washed four times with PBS. Washed samples were resuspended in $20 \mu \mathrm{l}$ of PBS and $10 \mu \mathrm{l}$ analyzed using an immunofluorescence microscopy as previously described [34].

\section{In vivo treatments}

Female BALB/c mice were maintained in pathogen-free conditions at the animal facility of the Institute of Food Sciences and used at the age of 8-14 weeks. The studies were approved by the National institutional review committee. Mice lightly anaesthetized with methoxuflurane were intranasally administered once/week for 8 weeks with 2.0 $\mu \mathrm{g}$ of LTB or $2 \times 10^{9}$ LTB-adsorbed spores. Control mice received only spores. Fecal pellets were collected at the end of each week to monitor the induction of the LTB-specific immunity. Mice were then sacrificed to collect, serum samples, spleens and mesenteric lymph nodes (MLN).

\section{Antibody analysis}

Fecal pellets were homogenized in PBS $+0.01 \%$ sodium azide $(100 \mathrm{mg} / \mathrm{ml})$ and centrifuged at $10,000 \mathrm{~g} 10 \mathrm{~min}$; supernatants were recovered and stored frozen or immediately analysed.

Fecal anti-LTB IgA, serum anti-LTB IgA, IgG, IgG1 and IgG2a subclasses antibodies were assayed by ELISA. LTB was coated onto U-bottomed microtiter plates at $1.0 \mu \mathrm{g} /$ well overnight at $4^{\circ} \mathrm{C}$. Plates were blocked with PBS containing 2\% BSA. After washing with PBS containing $0.05 \%$ Tween-20 serial twofold dilutions of serum or fecal supernatants were added to individual wells and incubated for $2 \mathrm{hr}$ at room temperature. The presence of antibodies was detected with peroxidase-conjugated rabbit anti-mouse IgA, IgG or isotype specific antibodies (Dako SpA, Milan, Italy) and the reaction developed with $1 \mathrm{mg} /$ $\mathrm{ml}$ o-phenylendiamine/ $\mathrm{HCl}$ substrate and $0.06 \% \mathrm{H}_{2} \mathrm{O}_{2}$. Results were expressed as absorbance values after blank 
subtraction or as reciprocal endpoint titer of the last dilution exhibiting an O.D. $\geq 0.1$ above negative controls.

\section{Cytokine secretion assay}

MLNs and spleens were passed through a stainless-steel wire mesh to dissociate cells. Removal of erytrocytes from spleen cells was performed by using a Tris-buffered ammonium chloride solution. Cells were cultured at $2.5 \times$ $10^{6} \mathrm{cells} / \mathrm{ml}$ in the presence/absence of LTB $(10 \mu \mathrm{g} / \mathrm{ml})$; after $72 \mathrm{hr}$, the supernatants were collected and analyzed for IFN- $\gamma$ and IL-4 protein levels by ELISA using commercial kits.

\section{Statistical analysis}

Differences among the various experimental groups were determined by the Kruskal-Wallis non-parametric test, followed by Dunn's Multiple Comparison Test for post test analysis.

\section{Competing interests}

The authors declare that they have no competing interests.

\section{Authors' contribution}

$\mathrm{Rl}$ - performed western, dot blot and immunofluorescence microscopy experiments and contributed to design experiments; TS - performed western and dot blot experiments; LT - performed the immunization experiments and analyzed the immune response; FM - performed the immunization experiments and analyzed the immune response; MDF - contributed to experiment design and manuscript writing; MR - contributed to experiment design and manuscript writing; ER - contributed to experiment design and wrote most of the manuscript. All authors read and approved the final manuscript.

\section{Acknowledgments}

We thank Luciano Di lorio for technical assistance. This work was supported by a grant (KBBE-476 2007-207948) from the EU 7th Framework to E.R.

\section{Author details}

${ }^{1}$ Department of Biology, Federico II University, Naples, Italy. ${ }^{2}$ Institute of Food Sciences, C.N.R, Avellino, Italy.

Received: 5 August 2013 Accepted: 20 October 2013

Published: 29 October 2013

\section{References}

1. Wu CH, Mulchandani A, Chen W: Versatile microbial surface-display for enviromental remediation and biofuels production. Trends Microbio/ 2008, 16:181-188.

2. Lee SY, Choi JH, Xu Z: Microbial cell-surface display. Trends Biotechnol 2003, 21:45-52.

3. Wells J: Mucosal vaccination and therapy with genetically modified lactic acid bacteria. Annu Rev Food Sci Technol. 2011, 2:423-45.

4. Villaverde A: Nanotechnology, biotechnology and microbial cell factories. Microb Cell Factories 2010, 9:53.

5. Isticato R, Cangiano G, Tran HT, Ciabattini A, Medaglini D, Oggioni MR, De Felice M, Pozzi G, Ricca E: Surface display of recombinant proteins on Bacillus subtilis spores. J Bacterio/ 2001, 183:6294-6301.

6. Cutting SM, Hong HA, Baccigalupi L, Ricca E: Oral vaccine delivery by recombinant spore probiotics. Intern. Rev. Immunol. 2009, 28:487-505.

7. McKenney PT, Driks A, Eichemberger P: The Bacillus subtilis endospore: assembly and functions of the multilayered coat. Nat Rev Microbiol 2013, 11:33-44.

8. Imamura D, Kuwana R, Takamatsu H, Watabe K: Proteins involved in formation of the outermost layer of Bacillus subtilis spores. J Bacteriol 2011, 193:4075-4080.
9. Knecht LD, Pasini P, Daunert S: Bacterial spores as platforms for bioanalytical and biomedical applications. Anal Bioanal Chem 2011, 400:977-989.

10. Cutting SM: Bacillus probiotics. Food Microbiol 2011, 28:214-220.

11. Mauriello EMF, Duc LH, Isticato R, Cangiano G, Hong HA, De Felice M, Ricca E, Cutting SM: Display of heterologous antigens on the Bacillus subtilis spore coat using CotC as a fusion partner. Vaccine 2004, 22:1177-1187.

12. Isticato R, Scotto Di Mase D, Mauriello EMF, De Felice M, Ricca E: Amino terminal fusion of heterologous proteins to $\operatorname{Cot} C$ increases display efficiencies in the Bacillus subtilis spore system. Biotechniques 2007, 42:151-156

13. Hinc K, Isticato R, Dembek M, Karczewska J, Iwanicki A, Peszyńska-Sularz G, De Felice M, Obukowski M, Ricca E: Expression and display of UreA of Helicobacter acinonychis on the surface of Bacillus subtilis spores. Microb Cell Fact 2010, 9:2.

14. Hinc K, Ghandili S, Karbalaee G, Shali A, Noghabi K, Ricca E, Ahmadian G: Efficient binding of nickel ions to recombinant Bacillus subtilis spores. Res Microbiol 2010, 161:757-764.

15. Detmer A, Glenting J: Live bacterial vaccines - a review and identification of potential hazards. Microb Cell Fact 2006, 5:23.

16. Yim S-K, Jung H-C, Yun C-H, Pan J-G: Functional expression in Bacillus subtilis of mammalian NADPH-cytochrome P450 oxidoreductase and its spore-display. Protein Expr Purif 2009, 63:5-11.

17. Cho EA, Kim EJ, Pan JG: Adsorption immobilization of Escherichia coli phytase on probiotic Bacillus polyfermenticus spores. Enzyme Microb Technol 2011, 49:66-71.

18. Sirec T, Strazzulli A, Isticato R, De Felice M, Moracci M, Ricca E: Adsorption of beta-galactosidase of Alicyclobacillus acidocaldarius on wild type and mutants spores of Bacillus subtilis. Microb Cell Fact 2012, 11:100.

19. Huang JM, Hong HA, Van Tong $H$, Hoang TH, Brisson A, Cutting SM: Mucosal delivery of antigens using adsorption to bacterial spores. Vaccine 2010, 28:1021-1030.

20. Douce G, Turcotte C, Cropley I, Roberts M, Pizza M, Domenghini M, et al: Mutants of Escherichia coli heat-labile toxin lacking ADP-ribosyltransferase activity act as nontoxic, mucosal adjuvants. Proc Natl Acad Sci USA 1995, 92:1644-8

21. Youngman $P$, Perkins $J B$, Losick $R$ : A novel method for the rapid cloning in Escherichia coli of Bacillus subtilis chromosomal DNA adjacent to Tn917 insertion. Mol Gen Genet 1984, 195:424-433.

22. Cutting S, Vander Horn PB: Genetic analysis. In Molecular Biological Methods for Bacillus. Edited by Harwood C, Cutting S. Chichester, UK: John Wiley and Sons; 1990:27-74.

23. Mauriello EMF, Cangiano G, Maurano F, Saggese V, De Felice M, Rossi M, Ricca E: Germination-independent induction of cellular immune response by Bacillus subtilis spores displaying the $C$ fragment of the tetanus toxin. Vaccine 2007, 25:788-793.

24. Kim J-M, Park S-M, Kim J-A, J-a P, M-h Y, Kim N-S, Bae J-L, Park GS, Jang J-S, Yang M-S, Kim D-H: Functional pentameric formation via coexpression of the Escherichia coli heat-labile enterotoxin B subunit and its fusion protein subunit with a Neutralizing Epitope of ApxIIA Exotoxin improves the mucosal immunogenicity and protection against challenge by Actinobacillus pleuropneumoniae. Clin Vaccine Immunol 2011, 18:2168-2177

25. Ricci S, Medaglini D, Rush CM, Marcello A, Peppoloni S, Manganelli R, Palú G, Pozzi G: Immunogenicity of the B monomer of Escherichia coli heatlabile toxin expressed on the surface of Streptococcus gordonii. Infect Immun 2000, 68:760-766.

26. Naclerio G, Baccigalupi L, Zilhao R, De Felice M, Ricca E: Bacillus subtilis spore coat assembly requires cotH gene expression. J Bacteriol 1996, 178:4375-4380.

27. Zilhao R, Naclerio G, Henriques AO, Baccigalupi L, Moran CP Jr, Ricca E: Assembly requirements and role of $\mathrm{CotH}$ during spore coat formation in Bacillus subtilis. J Bacteriol 1999, 181:2631-2633.

28. Kim H, Hahn M, Grabowski P, McPherson DC, Otte MM, Wang R, Ferguson CC, Eichenberger $P$, Driks A: The Bacillus subtilis spore coat protein interaction network. Mol Microbiol 2006, 59:487-502.

29. Nashar TO, Betteridge ZE, Mitchell RN: Evidence for a role of ganglioside GM1 in antigen presentation: binding enhances presentation of Escherichia coli enterotoxin B subunit (EtxB) to CD4(+) T cells. Int Immunol 2001, 13:541-551. 
30. Nashar TO, Webb HM, Eaglestone S, Williams NA, Hirst TR: Potent immunogenicity of the B subunits of Escherichia coli heat-labile enterotoxin: receptor binding is essential and induces differential modulation of lymphocyte subsets. Proc Natl Acad Sci USA 1996, 93:226-230.

31. Sambrook J, Fritsch EF, Maniatis T: Molecular cloning, laboratory manual. 2nd edition. NY, USA: Cold Spring Harbor Laboratory Press, Cold Spring Harbor; 1989.

32. Isticato R, Pelosi A, Zilhao R, Baccigalupi L, Henriques AO, De Felice M, Ricca E: CotC-CotU heterodimerization during assembly of the Bacillus subtilis spore coat. J Bacterio/ 2008, 190:1267-1275.

33. Isticato R, Pelosi A, De Felice M, Ricca E: CotE binds to CotC and CotU and mediates their interaction during spore coat formation in Bacillus subtilis. J Bacteriol 2010, 192:949-954.

34. Manzo N, Di Luccia B, Isticato R, D'Apuzzo E, De Felice M, Ricca E: Pigmentation and sporulation are alternative cell fates in Bacillus pumilus SF214. PLOS ONE 2013, 8(4):e62093. doi:10.1371/journal.pone.0062093.

doi:10.1186/1475-2859-12-98

Cite this article as: Isticato et al: Non-recombinant display of the B subunit of the heat labile toxin of Escherichia coli on wild type and mutant spores of Bacillus subtilis. Microbial Cell Factories 2013 12:98.

\section{Submit your next manuscript to BioMed Central and take full advantage of:}

- Convenient online submission

- Thorough peer review

- No space constraints or color figure charges

- Immediate publication on acceptance

- Inclusion in PubMed, CAS, Scopus and Google Scholar

- Research which is freely available for redistribution 